\title{
Closed External Subtalar Dislocation: A Case Report
}

\section{Achegri Abderrahim, Mohamed Nassiri, Yassine Chaouqui, Rachid Chafik, Mohamed Madhar, Hanane Elhaoury, Youssef Najeb}

Department of Traumato-Orthopedy A, University Hospital Center Mohamed VI, Faculty of Medicine and Pharmacy, Ibno Tofail Hospital, Marrakesh, Morocco

Email: achegriabderrahim123@gmail.com

How to cite this paper: Abderrahim, A., Nassiri, M., Chaouqui, Y., Chafik, R., Madhar, M., Elhaoury, H. and Najeb, Y. (2020) Closed External Subtalar Dislocation: A Case Report. Open Journal of Orthopedics, 10, 137-142.

https://doi.org/10.4236/ojo.2020.107015

Received: June 1, 2020

Accepted: July 14, 2020

Published: July 17, 2020

Copyright $\odot 2020$ by author(s) and Scientific Research Publishing Inc. This work is licensed under the Creative Commons Attribution International License (CC BY 4.0).

http://creativecommons.org/licenses/by/4.0/

\begin{abstract}
Subtalar dislocation is described as the simultaneous dislocation of the talo-calcaneal and talo-navicular joints without any tibio-talar or talar neck associated fractures. This injury is rare, and represents $1 \%$ of dislocations. We report the case of 28-year-old male patient, without any medical history, who had been involved in a sport accident causing a rare closed external subtalar dislocation without any bone fracture. An open reduction was indicated after failure of closed reduction and the X-ray control showed good joint congruence; the fixation was maintained for 6 weeks and then the rehabilitation was started. The evaluation was favorable, and we noted good functional results after a decline of 12 months.
\end{abstract}

\section{Keywords}

Closed External Dislocation, Subtalar Joint, Sport Injury

\section{Introduction}

Subtalar dislocation is a rare lesion, especially when it is pure. It represents only $1 \%$ of all dislocations observed in trauma [1] and $1 \%-2 \%$ of all dislocations, affecting predominantly middle-aged males [2]. The external variant is exceptional, compared to medial dislocation. It is defined as a simultaneous dislocation of the subtalar and talo-navicular joints without any fracture fracture.

Irreducible injuries have been reported in $0 \%$ to $47 \%$ of cases [2] [3] [4] [5]. The most common cause in any type of dislocation is the interposition of bone fragments from associated fractures, which has been described in up to $50 \%$ of cases [3]. In medial dislocations, the most common causes are either entrapment of the talar head within the extensor retinaculum or between the extensor ten- 
dons, but also other structures such as the deep peroneal neurovascular bundle can be involved. In contrast, either the posterior tibialis tendon or the flexor halluces longus are the typical anatomical structures interposed in the outer aspect of the talar neck in lateral dislocations [6].

This case report describes a closed lateral subtalar joint dislocation after a sport accident.

\section{Case Presentation}

28-year-old male patient, with no significant medical history, is admitted to the emergency department 2 hours after trauma to the right ankle following a sport accident (Tackle with a foot blocked against the ground, a forced valgus). The patient was in pain and total functional impairment of his ankle. Clinical admission examination found localized pain with deformation of the mediotarsal region without any wound (Figure 1), nor any neurovascular damage. The ankle $\mathrm{X}$-ray highlighted the external subtalar dislocation and no sign of any fractured bone was found (Figure 2).

The patient was immediately admitted to the operating theater where an immediate reduction was performed using sedation, during this procedure, the knee was kept flexed, so the gastrocnemius muscle was relaxed and constant counter-traction to the manoeuvres, then traction was applied, and at the same time a force in the opposite direction of the dislocation was performed, but the dislocation remained irreducible, thus the open reduction was indicated, the long hallux flexor tendon was interposed at the level of the talo-navicular joint, after his release we reduced the dislocation.

Clinical test after reduction has confirmed the instability of the subtalar joint without no neurovascular damage; that's why we opted a stabilization with a talonavicular K-wire associated with a posterior plaster cast, then X-ray control was achieved (Figure 3). A circular plaster was made 72 hours after the trauma allowing the skin condition to be checked, the restraint was maintained for six weeks, then rehabilitation was started, after a year of follow-up, the functional result was satisfactory.

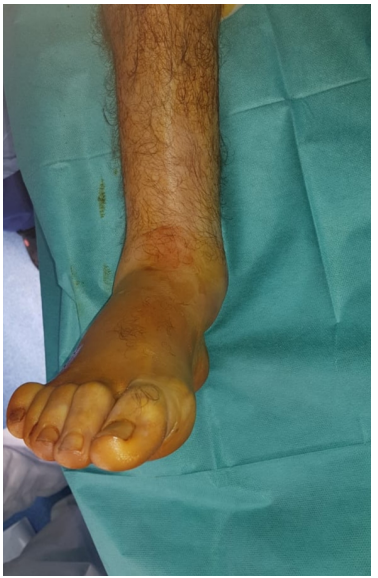

Figure 1. Showing left external subtalar dislocation. 


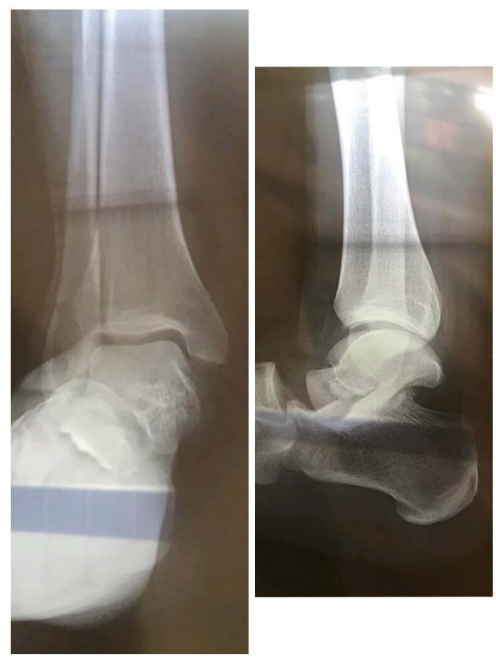

Figure 2. Anteroposterior and lateral X-ray of the left ankle showing external subtalar dislocation.

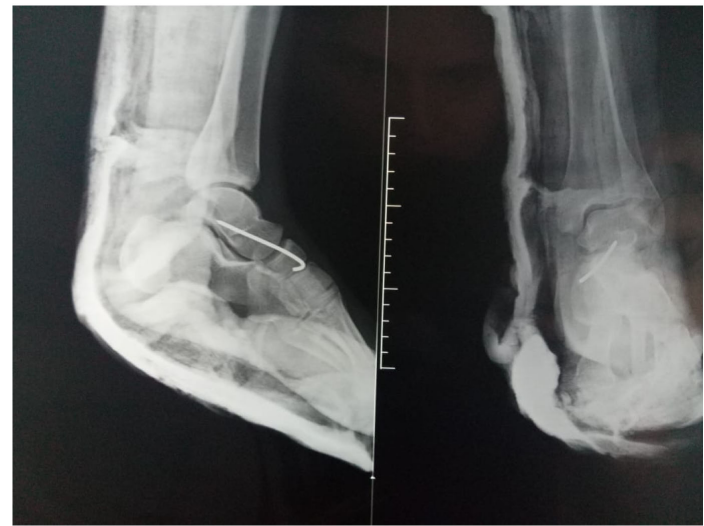

Figure 3. Anteroposterior and lateral X-ray of the left ankle showing reduction of the external subtalar dislocation.

\section{Discussion}

Subtalar dislocation is defined as a simultaneous dislocation of the talonavicular and talocalcaneal joints without any fracture [1] [7] [8]; so, the talus remains in place in the tibiofibular mortise, and the calcaneocuboid joint is intact [2].

External subtalar dislocation is a rare entity. Hey [9] in 1803, published the first observations. Baumgartner and Huguier [10] in 1907, carried out an experimental study on the mechanism of dislocation which made it possible to give an anatomopathological classification. It was Allieu [11], in 1967, who justified the term astragalo-scapho-calcaneal dislocation and described a different mechanism. The dislocation can be internal, external, posterior or anterior.

The sex ratio is three to four times greater in men [12] [13]. The current classification system uses well-known definitions [13] [14] [15]. With 80\% of subtalar dislocations cases, the medial form is the most common [1] [15]. It is predominant, because the subtalar joint presents a large displacement in inversion favoring its instability [4]. In addition, it seems that the lateral passive stabilizers (talo-calcanean 
and calcano-fibular ligaments) are weaker than the medial stabilizers (deltoid ligaments and medial talo-calcanean) [12] [13] [15].

Lateral dislocation results from forced eversion, the foot being locked in a rut with pressure on the lateral face of the leg [16]. At first, the deltoid ligament ruptures back and forth under the pressure of the head of the talus. Then, the interosseous talo-calcanean ligament tears by stretching, with talocalcaneal dislocation was followed by dorsal talonavicular ligament rupture by internal rotation of the leg, allowing the total escape of the foot under the talus outwards. This dislocation usually occurs as a result of high energy trauma. Swelling and edema appear quickly and can mask the deformity. The diagnosis is confirmed by lateral X-ray view but especially by anteroposterior X-ray view, showing the talus in place in the tibiofibular mortise while the foot is thrown inside. CT of the ankle can confirm the diagnosis and assess the associated osseocartilaginous lesions present in $20 \%$ to $30 \%$ of cases [16] [17]. The skin opening is internal in the lateral dislocations and occurs in $10 \%$ to $15 \%$ of cases [17]. Ischemia of the foot is more frequent in lateral dislocation because the posterior tibial artery is taken in the bridge at the talus [18].

Treatment consists of emergency reduction. Several reduction methods by external maneuvers have been described [2]. The commonly used technique requires anesthesia in order to obtain optimal muscle relaxation and thus reduce damage to the articular surfaces during manipulation. The ipsilateral knee is flexed to relax the gastrocnemius muscles. A firm longitudinal traction of the foot is applied with a contraction on the leg combined initially with the accentuation of the deformation. This is followed by a reverse of the deformation (eversion for medial dislocation and inversion for lateral dislocation). Direct pressure on the head of the talus helps for reduction that makes audible noise [1] [19]. Abrupt maneuvers, excessive force and multiple closed reduction attempts should be avoided so as not to generate additional soft tissue damage [8]. Once the reduction has been achieved, the neurovascular and stability status of the ankle should be assessed [8] [19].

Initial immobilization is done with either a below-the-knee splint or bivalve cast to avoid increased compartment pressures in the affected foot due to swelling. Several authors [2] [4] proposed a four to six week period of time; however, a longer time is needed if associated injuries are present [2] [20]. In contrast, in cases of pure dislocations without instability, early range of motion is advocated as early as three weeks after immobilisation [2] [5].

The irreducibility must make suspect an interposition, in these cases, an open reduction is required as early as possible in order to avoid further soft tissue as well as neurovascular damage. In lateral dislocations, the incision should be located between the medial malleolus and the head of the talus [21]. Once reduction is achieved, if there is no associated instability, the management is not different from a closed reduction except for wound care requirements.

Stabilization by K-wire, associated with a 6 -week plastered cast, carried out by some authors, is suspected of stiffening but is a guarantee against instability [2]. 
The prognosis is good if the reduction is made within hours of the accident.

The most frequent complications are represented by: stiffness, osteoarthritis, a vascular necrosis of the talus and instability of the subtalar joint [2] [8]. The risk of osteoarthritis is all the greater as displacement persists after reduction or if the patient has an associated joint fracture, more frequent with lateral dislocation.

\section{Conclusion}

Pure subtalar disjunction is a rare injury that occurs after high energy trauma. And the external variant remains exceptional. Emergency management is necessary after a clinical, skin, neurovascular and radiological examination in order to urgently achieve a reduction by external maneuvers or an open reduction in case of bone or tendon interposition.

\section{Patient Consent}

The patient was informed that data from his case would be submitted for publication, and an informed consent was obtained.

\section{Conflicts of Interest}

The authors declare no conflicts of interest regarding the publication of this paper.

\section{References}

[1] Gantsos, A., Giotis, D. and Giannoulis, D.K. (2013) Conservative Treatment of Closed Subtalar Dislocation: A Case Report and 2 Years Follow-Up. Foot, 23, 107-110. https://doi.org/10.1016/j.foot.2013.06.001

[2] DeLee, J.C. and Curtis, R. (1982) Subtalar of the Foot. The Journal of Bone and Joint Surgery. American Volume, 64, 433-437. https://doi.org/10.2106/00004623-198264030-00014

[3] Bibbo, C., Anderson, R.B. and Davis, W.H. (2003) Injury Characteristics and the Clinical Outcome of Subtalar Dislocations: A Clinical and Radiographic Analysis of 25 Cases. Foot \& Ankle International, 24, 158-163. https://doi.org/10.1177/107110070302400210

[4] Zimmer, T.J. and Johnson, K.A. (1989) Subtalar Dislocations. Clinical Orthopaedics and Related Research, 238, 190-194. https://doi.org/10.1097/00003086-198901000-00027

[5] Lasanianos, N.G., Lyras, D.N., Mouzopoulos, G., Tsutseos, N. and Garnavos, C. (2011) Early Mobilization after Uncomplicated Medial Subtalar Dislocation Provides Successful Functional Results. Journal of Orthopaedics and Traumatology, 12, 37-43. https://doi.org/10.1007/s10195-011-0126-2

[6] Waldrop, J., Ebraheim, N.A., Shapiro, P. and Jackson, W.T. (1992) Anatomical Considerations of Posterior Tibialis Tendon Entrapment in Irreducible Lateral Subtalar Dislocation. Foot Ankle, 13, 458-461. https://doi.org/10.1177/107110079201300805

[7] Gaba, S., Kumar, A., Triha, V., Das, S., et al. (2017) Luxation poste-rieure de l'articulation sous-astragalienne sans fracture associee: Rapport de cas et revue de la litterature. Journal of Clinical and Diagnostic Research, 11, 1-2. 
[8] Prada-Canizares, A., Aunon-Martin, I., Rico, J.V., et al. (2016) Subtalar Dislocation: Management and Prognosis for an Uncommon Orthopaedic Condition. International Orthopaedics, 40, 999-1007. https://doi.org/10.1007/s00264-015-2910-8

[9] Hey, P. (1801) Bulletin de la faculté de Médecine de Paris. (In Press)

[10] Baumgartner, A. and Huguier, A. (1907) Les luxations sous-astragaliennes. Revue de Chirurgie, 35, 372-395.

[11] Allieu, Y. (1967) Thèse Médecin Montpellier. La luxation astragalo-scaphocalcanéenne interne: Etude expérimentale du mécanisme à propos de 10 cas. (In Press)

[12] Rida-Allah, B., Aitbenali, H., Mahfoud, M., et al. (2015) Rare Case of Pure Medial Subtalar Dislocation: Conservative Treatment and 32 Months Follow-Up. Journal of Emergencies, Trauma, and Shock, 8, 174-175. https://doi.org/10.4103/0974-2700.145419

[13] Pesce, D., Wethern, J. and Patel, P. (2011) Rare Case of Medical Subtalar Dislocation from a Low-Velocity Mechanism. European Journal of Emergency Medicine, 6, 121-124. https://doi.org/10.1016/j.jemermed.2008.04.049

[14] Perouse D, Basile A, Terrence J, et al. (2007) Dislocation sous-talienne anteromediale. The Journal of Foot and Ankle Surgery, 46, 52-54.

[15] Inokuchi, S., Hashimoto, T., Usami, N., et al. (1996) Subtalar Dislocation of the Foot. Foot, 6, 168-174. https://doi.org/10.1016/S0958-2592(96)90016-4

[16] Marotte, J.H., Lord, G., Samuel, P. and Moati, J.C. (1979) Les luxations sous astragaliennes externes: A propos de 4 cas. Chirurgie, 105, 389-392.

[17] Meyer, J.M. and Hoffmeyer, P. (1985) La luxation sous-astragalienne. Médecine et Hygiène, 43, 1520-1522.

[18] Tricoire, J.L., Colombier, J.A., Chiron, P., Duraffour, H., Puget, J. and Utheza, G. (1989) Strasbourg, 9ème Congrès de Chirurgie d'Urgence. Les luxations sous-astragaliennes: Appréciation pronostique, attitude thérapeutique.

[19] Ruhlmann, F., Poujardieu, C., Vernois, J., et al. (2017) Isolated Acute Traumatic Subtalar Dislocations: Review of 13 Cases at a Mean Follow-Up of 6 Years and Literature Review. The Journal of Foot and Ankle Surgery, 56, 201-207.

https://doi.org/10.1053/j.jfas.2016.01.044

[20] Horning, J. and DiPreta, J. (2009) Subtalar Dislocation. Orthopedics, 32, 904-908. https://doi.org/10.3928/01477447-20091020-17

[21] Saltzman, C. and Marsh, J.L. (1997) Hindfoot Dislocations: When Are They Not Benign? Journal of the American Academy of Orthopaedic Surgeons, 5, 192-198. https://doi.org/10.5435/00124635-199707000-00002 